\title{
Catha edulis Forsk and Ascorbic Acid Effects on Hematological Indices in Rat
}

\author{
Abebaye Aragaw Leminie' \\ Tesfaye Tolessa Dugul (D)' \\ Eyasu Makonnen Eshetu ${ }^{2}$ \\ Daniel Seyifu Melka ${ }^{3}$ \\ 'Department of Physiology, Addis Ababa \\ University, College of Health Sciences, \\ Addis Ababa, Ethiopia; ${ }^{2}$ Department of \\ Pharmacology, Addis Ababa University, \\ College of Health Sciences, Addis Ababa, \\ Ethiopia; ${ }^{3}$ Department of Biochemistry, \\ Addis Ababa University, College of \\ Health Sciences, Addis Ababa, Ethiopia
}

Background: The prevalence of chewing Catha edulis Forsk and the use of ascorbic acid is increasing from time to time. Their subchronic effects on hematological indices are not well examined. The present study was aimed to investigate their subchronic effects on hematological indices in rats.

Materials and Methods: A total of 36 adult (7-8 weeks) wild-type rats weighing between 213 and 229g were used in this study. They received Catha edulis Forsk extract (Ce) (100 milligrams/kilogram, 200 milligram/kilogram and 300 milligram/kilogram b.w), Catha edulis Forsk juice $(2.5 \mathrm{~mL} / \mathrm{kg}$ ), ascorbic acid (AA 200 milligram/kilogram), and 2\% tween 80 in distilled water (T80W- v/v) for twelve weeks. Hematological indices were measured with Sysmex KX-21. Data were analyzed by SPSS version 21.0 and Microsoft Excel.

Results: Neutrocytes $(\mathrm{p}<0.01)$, lymphocytes $(\mathrm{p}<0.05)$, plateletcrit $(\mathrm{p}<0.05)$, average size of platelets $(\mathrm{p}<0.05)$, platelet size variability $(\mathrm{p}<0.01)$, platelet-large cell ratio $(\mathrm{p}<0.05)$ and neutrocytes/lymphocytes ratio $(\mathrm{p}<0.001)$ were significantly greater, while hemoglobin concentration per red blood cell $(p<0.05)$ and hemoglobin concentration per volume of red blood cells were significantly reduced $(\mathrm{p}<0.05)$ in rats received khat. The red cell distribution width $(\mathrm{p}<0.05)$, platelet size variability $(\mathrm{p}<0.05)$ and platelet-large cell ratio $(\mathrm{p}<0.01)$ were significantly greater in rats received ascorbic acid.

Conclusion: Crude Catha edulis Forsk extract and juice changed some hematological indices and increased platelet activities. The platelet activity was also increased by ascorbic acid. The mechanisms for these changes need to be investigated.

Keywords: Catha edulis Forsk, ascorbic acid, hematological indices

\section{Introduction}

Catha Edulis Forsk (CEF) is one of the stimulants chewed by the people of Ethiopia. ${ }^{1}$ It is extensively chewed regardless of its adverse effects. Anemia, cancer, schizophrenia, anxiety, depression, diabetes mellitus, and inflammation are more common among CEF chewers. ${ }^{2}$ Hematological changes are observed in these diseases. $^{3}$ It also affects the therapeutic effects of drugs. ${ }^{4,5}$ Certain disease conditions are aggravated by $C E F$. ${ }^{6,7}$ Cathinone, Cathine, tannins, ascorbic acid (AA), and electrolytes are some of the composites in it. ${ }^{8,9}$ The compounds found in this psychostimulant are expected to affect hematological indices.

Its subacute effects on hematologic indices have been evaluated in an animal model. Most of the findings are controversial and incomplete. ${ }^{10}$ AA has been taken as a protective agent against different diseases effects. ${ }^{11-14}$ The purpose of taking $\mathrm{AA}$ is to regulate hematological and other changes in disease conditions. Acute administration of AA reduces oxidative stress and increases blood cell counts. ${ }^{15}$ 
Yet, no studies have been conducted on subchronic hematological effects of $C E F$ and AA.

Investigate the subchronic effects of $C E F$ and $\mathrm{AA}$ on hematological indices in rats is the aim of the current study.

\section{Materials and Methods}

Diethyl ether, chloroform (Sigma-Aldrich, Germany), Tween 80 , AA, and $70 \%$ ethanol were chemicals used in this study. These chemicals were purchased from local suppliers in Addis Ababa, Ethiopia.

\section{Plant Materials Collection}

Bundles of fresh $C E F$ leaves $(9 \mathrm{~kg})$ were collected from Aweday, Eastern Ethiopia. The plant specimen was identified and a voucher number (October 16, 2018, AA002) was given. The leaves have been deposited at the National Herbarium of Ethiopia, Addis Ababa University.

\section{Plant Material Extraction}

After the edible parts of the leaves were separated and washed with tap water, the leaves were freeze-dried at $-20^{\mathrm{O}} \mathrm{C}^{16}$ for 2 days and crushed using mortar and pestle. Two hundred grams of freeze-dried crushed leaves were placed into a conical flask wrapped with aluminum foil. A total of $400 \mathrm{~mL}$ organic solvents, ie, $300 \mathrm{~mL}$ diethyl ether and $100 \mathrm{~mL}$ chloroform $(3: 1 \mathrm{v} / \mathrm{v}$ ratio) were added into the flask. The mixture was shaken under dark conditions for 48hrs using a rotary shaker (New Brunswick Scientific Co, USA) at $120 \mathrm{rpm}$ and $20^{\circ} \mathrm{C}$. It was then filtered initially using cotton gauze followed with grade I Whatman filter paper (Cat No 1001 150). The organic solvents were then removed through evaporation using Rota-vapor under a controlled temperature of $36^{\circ} \mathrm{C}$, rotation of $120 \mathrm{rev} / \mathrm{min}$, and $240 \mathrm{Pascal}$ negative pressure. The water in the extract was removed through lyophilization and the dry residue was weighed using an analytical balance and stored in a desiccator till used. The $C E F$ juice (ChJ) was prepared from $12 \mathrm{~g} / \mathrm{kg}$ b.w of fresh leaves using $2 \%$ tween 80 in distilled water (v/v). In this study, 12 grams of fresh $C E F$ leaves for a rat weighing 1 kilogram was taken as a selected dose. The leaf extract for each rat was calculated according to the weight of each rat (calculated dose $=$ Weight of the rat $(\mathrm{g}) *$ the selected dose $(\mathrm{g}) /$ $1000(\mathrm{~g}))$. The fresh leaves with tween 80 in distilled water $(\mathrm{T} 80 \mathrm{~W})$ were crushed using a blender machine. The juice was then squeezed and filtered using the gauze and grade I Whatman filter paper. The T80W used to extract the given weight of the leaves was determined based on the total weight of each rat and vehicle volume used ( $2.5 \mathrm{~mL} / \mathrm{kg}$ b.w).

\section{Animal}

A total of 36 adult wild-type male white albino rats aged between 7 and 8 weeks were used. Their weight was ranged between 213 and 229g. They were purchased from Laboratory Animal Breeding Section of the Ethiopian Public Health Institution. Three rats per plastic cage under natural light and dark (12:12hrs) cycles at room temperature were housed. Pellet and water were available ad libitum throughout the experimental period. Rats were weighed twice a week to ensure appropriate dosing based on body weight changes. Department of Medical Physiology and Institutional Review Board (IRB) Committee of the College of Health Sciences approved the study. Rules in animal care and use $^{17}$ have been used during animal handling.

\section{Grouping and Dosing}

Rats were randomly assigned into six groups (n=6/group) and received T80W, CEF extract (Ce) 100 milligram/kilogram, 200 milligram/kilogram and 300 milligrams/kilogram, AA (200 milligram/kilogram), and CEF juice (ChJ $2.5 \mathrm{~mL} /$ $\mathrm{kg}$ ). They were administered for twelve weeks. T80W was used as a vehicle and the quantity for $C E F$ extract and AA were selected based on previous reports. ${ }^{18,19}$

\section{Test Substances and Volume Determination}

Fresh $C E F$ extract, $\mathrm{AA}, \mathrm{ChJ}$, and vehicle were prepared every day. $C E F$ extract was dissolved in T80W. AA was powdered and dissolved in T80W to make a stock solution of $80 \mathrm{mg} / \mathrm{mL}$. Dose of the extract administered in each rat was calculated based on the total body weight (b.w) of each rat. Appropriate standard vehicle volume $(2.5 \mathrm{~mL} / \mathrm{kg}$ b.w) was used to determine how much volume was used to dissolve the calculated dose of $C E F$ extract and AA. Each rat in its respective group received a single daily oral vehicle, $C E F$ extract, $C h J$, and AA. $1 \mathrm{~mL}$ was the final volume and all these were administered orally.

\section{Blood Collection}

The procedure used by Ketema et $\mathrm{al}^{20}$ was used during blood withdrawal. Three milliliters of whole blood were collected from each rat through cardiac puncture after they were 
anesthetized using sodium pentobarbital ( $1 \mathrm{~mL} / \mathrm{kg}$ b.w) Blood was collected at 9:am and put into a tube containing ethylenediaminetetraacetic acid (EDTA) 24 hours after the last administration of test substances. Total leukocytes, Neutrocytes (NEUT), lymphocytes (LYMPH), monocytes (MONO), Eosinophils (EO), basophils (BASO), Hemoglobin (Hg), Hematocrit (HCT), Red blood cell size (RBCs), and red blood cell size variability (RsV) were analyzed by CBC machine (Sysmex KX-21). Hemoglobin concentration per red blood cell (HgpRBC), Hemoglobin concentration per volume of red blood cells (HgpvRBCs), platelet, Platelet size variability (PsV), plateletcrit (PCT), and platelet-large cell ratio (P-LCR) were also analyzed. NEUT to LYMPH ratio (NLR) was determined from quantified cells.

\section{Data Analysis}

The statistical analysis was done using SPSS version 21.0 and graphs were plotted using Microsoft Excel. Mean $\pm \mathrm{S}$. E.M have been used to express the values. Differences in hematological indices between three and more groups were analyzed using one-way ANOVA followed by Tukey's post hoc analysis. An independent $t$-test was also used in this study to compare values obtained from only two groups such as the test versus control groups.

\section{Results}

Significant differences in total leukocyte count $(\mathrm{F}(5,30)$ $=1.61, \mathrm{p}>0.05)$, MONO $(\mathrm{F}(5,30)=1.37, \mathrm{p}>0.05)$, EO $(\mathrm{F}$ $(5,30)=1.64, \mathrm{p}>0.05)$ and BASO $(\mathrm{f}(5,30)=1.39, \mathrm{p}>$ $0.05)$ were not observed between groups. Significant difference in NEUT $(\mathrm{F}(5,30)=6.42, \mathrm{P}<0.001)$, LYMPH $(\mathrm{F}$
$(5,30)=3.27, \mathrm{p}<0.05)$ and $\operatorname{NLR}(\mathrm{F}(5,30)=6.97, \mathrm{p}<$ $0.001)$ was observed between groups.

NEUT and NLR in rats receiving CEF extract were significantly higher when compared with the T80W ( $\mathrm{t}_{(26.07)}$ $=-3.72, \mathrm{p}<0.01,95 \% \mathrm{CI}[-11.69,-3.37]$ and $\mathrm{t}_{(24.72)}=-3.22$, $\mathrm{p}<0.01,95 \%$ CI $[-20.28,-4.44])$ and AA (t ${ }_{(7.44)}=-2.34$, $\mathrm{p}<0.05 ; 95 \%$ CI $[-9.25,-0.11]$ and $\mathrm{t}_{(27.99)}=-2.06, \mathrm{p}<0.05$; 95\% CI [-17.06,-0.06], respectively) as shown in Figure 1.

Rats received Ce100 milligram/kilogram had significantly higher NEUT $(p<0.001,95 \%$ CI $[7.09,29.21])$ and NLR ( $p<0.001,95 \%$ CI [13.46, 54.49]) compared with rats received T80W (Table 1). NEUT and NLR in rats received Ce100 milligram/kilogram were also significantly higher when compared with rats received AA $(\mathrm{p}<0.01$, 95\% CI [4.25, 26.37] and $\mathrm{p}<0.01,95 \%$ CI [9.65, 50.69], respectively). However, LYMP was significantly less in this group of rats when compared with rats received T80W ( $\mathrm{p}<0.05,95 \%$ CI [-31.12,-0.89]) (Table 1).

Significant differences in $\mathrm{RBC}$ count $\left(\mathrm{F}_{(5,30)}=2.75, \mathrm{p}<\right.$ $0.05), \operatorname{HGB}\left(\mathrm{F}_{(5,30)}=3.69, \mathrm{p}\right.$-value less than 0.05), HCT $(\mathrm{F}$ $(5,30)=3.60, \mathrm{p}<0.05)$ and $\operatorname{RBCS}\left(\mathrm{F}_{(5,30)}=4.07, \mathrm{P}\right.$ value less than 0.01) were observed between groups. Post hoc analysis results indicated no significant differences in RBC count, $\mathrm{Hg}$ concentration, and HCT (Table 1).

HgpRBC in rats received the Ce was significantly less than in those received $\mathrm{T} 80 \mathrm{~W}\left(\mathrm{t}_{(24.27)}=3.57, \mathrm{p}<0.05\right.$; 95\% CI $[0.41,1.52])$ as shown in Figure 1. Rats received Ce 100 milligram/kilogram $(p<0.05,95 \%$ CI [0.07, 11.63]), Ce 200 milligram/kilogram (p value less than $0.05,95 \%$ CI $[-11.97,-0.41])$ and Ce 300 milligram/kilogram ( $\mathrm{p}<0.05,95 \% \mathrm{CI}[-12.73,-1.17])$ had significantly less RBCS than received AA 200 milligram/kilogram.

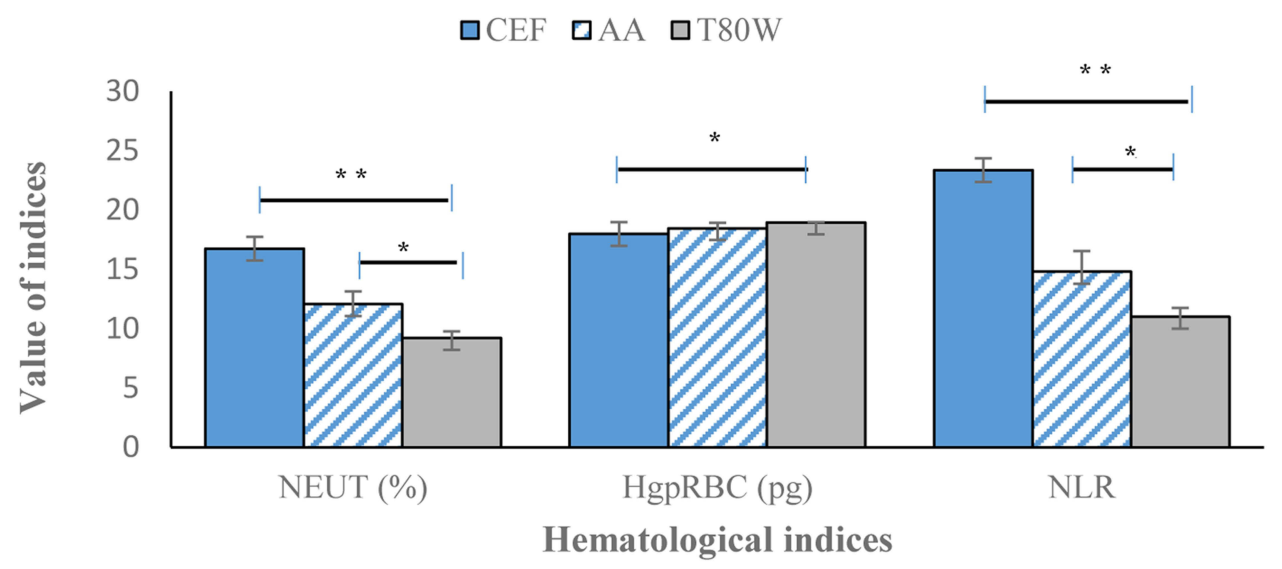

Figure I Effects of Catha edulis Forsk on HgPRBC, NEUT, and NLR in Rats. Each bar represents the mean \pm SEM of these indices in rats received AA, T80W, and khat. **Statistical difference at $p<0.01$ and *Statistical difference at $p<0.05$ when rats received CEF, AA and T80W were compared to each other.

Abbreviations: CEF, Catha edulis Forsk; AA, ascorbic acid; HgpRBC, hemoglobin concentration per red blood cell; NEUT, neutrocyte; NLR, neutrocyte to lymphocyte ratio. 
Table I Effect of Catha edulis Forsk and Ascorbic Acid on Hematological Indices

\begin{tabular}{|c|c|c|c|c|c|c|}
\hline \multirow[t]{2}{*}{ Parameter } & \multicolumn{6}{|c|}{ Group } \\
\hline & T80W & AA200 mg/kg & Cel $00 \mathrm{mg} / \mathrm{kg}$ & $\mathrm{Ce} 200 \mathrm{mg} / \mathrm{kg}$ & Ce300 mg/kg & ChJ2.5 mL/kg \\
\hline $\mathrm{WBC}\left(10^{3} / \mu \mathrm{L}\right)$ & $9.06 \pm 0.56$ & $10.57 \pm 1.83$ & $7.02 \pm 0.68$ & $6.91 \pm 0.82$ & $8.20 \pm 1.01$ & $8.25 \pm 1.03$ \\
\hline MONO (\%) & $4.07 \pm 0.43$ & $4.53 \pm 0.83$ & $3.88 \pm 0.49$ & $3.00 \pm 0.46$ & $2.97 \pm 0.10$ & $3.33 \pm 0.64$ \\
\hline EO (\%) & $0.89 \pm 0.21$ & $1.30 \pm 0.54$ & $0.50 \pm 0.05$ & $1.12 \pm 0.07$ & $0.63 \pm 0.09$ & $0.67 \pm 0.06$ \\
\hline BASO (\%) & $0.30 \pm 0.04$ & $0.10 \pm 0.04$ & $0.17 \pm 0.06$ & $0.18 \pm 0.04$ & $0.25 \pm 0.12$ & $0.15 \pm 0.03$ \\
\hline NEUT & $9.23 \pm 0.55$ & $12.06 \pm 1.08$ & $27.37 \pm 5.60 * * * \mathrm{ee}$ & $12.87 \pm 1.50$ & $11.42 \pm 1.99$ & $15.32 \pm 0.78$ \\
\hline LYMP (\%) & $84.42 \pm 3.21$ & $82.65 \pm 2.35$ & $68.42 \pm 6.40 *$ & $82.48 \pm 1.76$ & $86.20 \pm 2.97$ & $80.28 \pm 2.31$ \\
\hline NLR (\%) & $10.99 \pm 0.76$ & $14.79 \pm 1.74$ & $44.96 \pm 10.92 * * * \mathrm{ee}$ & $15.79 \pm 2.14$ & $13.39 \pm 2.67$ & $19.25 \pm 1.41$ \\
\hline $\operatorname{RBC}\left(10^{6} / \mu \mathrm{L}\right)$ & $8.75 \pm 0.16$ & $6.66 \pm 1.21$ & $9.28 \pm 0.47$ & $8.84 \pm 0.218$ & $9.17 \pm 0.48$ & $6.55 \pm 1.21$ \\
\hline $\mathrm{Hg}(\mathrm{g} / \mathrm{dL})$ & $16.95 \pm 0.26$ & $12.22 \pm 2.08$ & $16.93 \pm 0.48$ & $15.80 \pm .52$ & $|7.10 \pm 0.5|$ & $11.53 \pm 2.30$ \\
\hline RBCs (\%) & $48.46 \pm 0.59$ & $35.07 \pm 5.78$ & $48.88 \pm I .11$ & $45.77 \pm 0.71$ & $48.28 \pm 0.72$ & $34.88 \pm 6.19$ \\
\hline sRBCs (fL) & $54.13 \pm 0.49$ & $59.24 \pm 2.48$ & $53.38 \pm 0.42 \mathrm{e}$ & $53.05 \pm 0.98^{e}$ & $52.28 \pm 0.48^{\mathrm{e}}$ & $57.08 \pm 1.76$ \\
\hline $\mathrm{HgpRBC}(\mathrm{pg})$ & $18.94 \pm 0.05$ & $18.47 \pm 0.46$ & $18.42 \pm 0.46$ & $18.37 \pm 0.48$ & $18.67 \pm 0.47$ & $17.78 \pm 0.58$ \\
\hline HgpRBCs (g/dL) & $35.13 \pm 0.24$ & $33.01 \pm 0.99$ & $34.53 \pm 0.75$ & $34.50 \pm 0.94$ & $35.40 \pm 0.49$ & $31.42 \pm 1.30 *$ \\
\hline $\operatorname{RsV}(\mathrm{fL})$ & $31.73 \pm 0.56$ & $34.11 \pm 0.55^{*}$ & $33.38 \pm 0.56$ & $31.31 \pm 0.32$ & $34.02 \pm 0.75^{*}$ & $30.92 \pm 0.29$ \\
\hline $\operatorname{PLT}\left(10^{3} / \mu \mathrm{L}\right)$ & $476.83 \pm 22$ & $381.83 \pm 102.6$ & $509.00 \pm 111.7$ & $543.17 \pm 90.9$ & $607.33 \pm 126.3$ & $379.17 \pm 119.1$ \\
\hline РCT (\%) & $0.35 \pm 0.03$ & $0.38 \pm 0.08$ & $0.65 \pm 0.03 * \mathrm{e}$ & $0.43 \pm 0.07$ & $0.65 \pm 0.03 * \mathrm{e}$ & $0.37 \pm 0.08$ \\
\hline $\operatorname{aPs}(\mathrm{fL})$ & $8.39 \pm 0.24$ & $8.90 \pm 0.47$ & $8.29 \pm 0.08$ & $8.11 \pm 0.06$ & $11.37 \pm .1 .36 *$ & $8.90 \pm 0.92$ \\
\hline $\mathrm{PsV}(\mathrm{fL})$ & $9.28 \pm 0.26$ & $10.28 \pm\left. 0.2\right|^{*}$ & $9.30 \pm 0.10$ & $8.95 \pm 0.28$ & $|0.89 \pm 0.5|^{* *}$ & $9.33 \pm 0.08$ \\
\hline P-LCR (\%) & $13.48 \pm 0.87$ & $18.79 \pm 0.8 * *$ & $13.28 \pm 0.91^{\mathrm{e}}$ & $12.48 \pm 0.74^{\mathrm{e}}$ & $13.47 \pm 0.86^{\mathrm{e}}$ & $18.01 \pm 1.15^{*}$ \\
\hline
\end{tabular}

Notes: Hematological indices in rats ( $\mathrm{n}=6 / \mathrm{group})$ receivedT80W, AA $200 \mathrm{mg} / \mathrm{kg}, \mathrm{Ce}(100 \mathrm{mg} / \mathrm{kg}, 200 \mathrm{mg} / \mathrm{kg}$, and $300 \mathrm{mg} / \mathrm{kg})$ and ChJ $2.5 \mathrm{~mL} / \mathrm{kg}$ represented as mean $\pm \mathrm{SEM}$ of. ***Statistical difference at $\mathrm{p}<0.00 \mathrm{I}$; **Statistical difference at $\mathrm{p}<0.01$ and $*$ Statistical difference at $\mathrm{p}<0.05$ when rats received Cel00mg/kg, Ce200mg/kg, Ce300mg/kg, ChJ $2.5 \mathrm{~mL} / \mathrm{kg}$ and AA $200 \mathrm{mg} / \mathrm{kg}$ were compared with rats received T80W. ${ }^{\text {ee }}$ statistical difference at $p<0.01$ and ${ }^{e}$ statistical difference at $p<0.05$ when rats received Cel $00 \mathrm{mg} / \mathrm{kg}$, Ce200 mg/kg, Ce300 mg/kg, ChJ $2.5 \mathrm{~mL} / \mathrm{kg}$ were compared with rats received AA $200 \mathrm{mg} / \mathrm{kg}$.

Abbreviations: Ce, Catha edulis Forsk extract; $\mu \mathrm{L}$, microliter; sRBCs, size of red blood cells; dL, deciliter; fL, femtoliter; NEUT, Neutrocytes; Pg, picogram; NLR, Neut to Lymph ratio; $\mathrm{Hg}$, hemoglobin; $\mathrm{HgpRBC}$, hemoglobin concentration per red blood cell; HgpvRBCs, hemoglobin concentration per volume of red blood cells; PCT, plateletcrit; RsV, red blood cell size variability; PsV, platelet size variability; aPs, average platelet size; P-LCR, platelet-large cell ratio; T80W, tween 80 in distilled water; mg/kg, milligram/ kilogram; AA, ascorbic acid; kh], Catha edulis Forsk juice.

$\mathrm{RsV}$ in rats received Ce300 milligram/kilogram $(\mathrm{p}<0.05$, $95 \%$ CI $[0.01,4.57])$ and AA $(\mathrm{p}<0.05,95 \%$ CI $[0.10$, 4.66]) was significantly higher when compared with rats received $\mathrm{T} 80 \mathrm{~W}$ (Table 1).

Significant differences were observed in aPs $\left(\mathrm{F}_{(5,30)}\right.$ $=3.82, \mathrm{p}<0.01)$, PCT $(\mathrm{F}(5,30)=5.51$, P-value less than $0.01), \operatorname{PsV}\left(F_{(5,30)}=7.14, \mathrm{p}<0.001\right)$ and P-LCR $(\mathrm{F}$ $(5,30)=8.95, \mathrm{p}<0.001)$ between groups. But, no significant difference in platelet count $\mathrm{F}_{(5,30)}=0.79$, $\mathrm{p}>0.05$ ) among the groups was observed. PCT was higher in rats received Ce100 milligram/kilogram and Ce300 milligram/kilogram compared to rats received T80W (P-value less than 0.05, $95 \mathrm{CI}[0.05,0.57]$ and $\mathrm{p}<0.05,95 \%$ CI [0.05, 0.57], respectively). PCT in these groups was also significantly higher when compared to rats received AA $(\mathrm{p}<0.05,95 \%$ CI [0.01, $0.53]$ and $\mathrm{p}<0.05,95 \%$ CI [0.01, 0.53], respectively). $\mathrm{PsV}$ in rats received Ce300 milligram/kilogram was significantly greater than in received T80W $(\mathrm{p}<00.01$, 95\% CI [0.31, 2.80]). Rats received Ce100 milligram/ kilogram ( $\mathrm{p}<0.01,95 \%$ CI [-9.43, -1.57]), Ce200 milligram/kilogram (p-value less than 0.001, 95\% CI $[-10.23,-2.37])$ and Ce300 milligram/kilogram $(p<$ $0.01,95 \%$ CI $[-9.25,-1.39])$ had significantly less P-LCR than rats received ascorbic acid. As shown in the table, rats receiving $\mathrm{ChJ} 2.5 \mathrm{~mL} / \mathrm{kg}$ had higher $\mathrm{P}-\mathrm{LCR}$ than in rats received $\mathrm{T} 80 \mathrm{~W}$ (p- vale was less $0.05,95 \%$ CI $[0.60,8.46]$.

\section{Discussion}

In this study, total leukocytes, monocytes, basophils, and eosinophils were not affected by crude $C E F$ extract and juice (Table 1). Alele et $\mathrm{al}^{21}$ also revealed that total leukocyte was not affected by this extract. However, BinJaliah et $\mathrm{al}^{10}$ and Ketema et $\mathrm{al}^{20}$ revealed that total leukocyte was reduced by $C E F$ extract indicating that this extract suppressed immunity. Disagreement between these findings might be because of variation in extraction solvent, duration of administration, and animal species used to see the effects. 
Even though the statistical difference in the total leukocytes did not observe between rats receiving the vehicle and AA in this study, previous studies indicated that white cell count was significantly increased by vitamin C. ${ }^{19,22}$ In the previous study, Vitamin C (30 milligrams/kilogram and 70 milligrams/kilogram) was given for four weeks twice per day. However, it was administered (200 milligrams/ kilogram) for twelve weeks per day in the current evaluation. Discrepancy between these findings might be attributed to the dose and duration of administration. These findings showed that vitamin $\mathrm{C}$ administered for a short period with a minimum dose increases white blood cells. In our study, neutrocytes and NLR were increased significantly while lymphocytes count was reduced, particularly by the lower dose. The tolerance effects of $C E F$ might be less at the lower dose. Although much has not been done on the tolerance effects of $C E F$, a previous study showed that $C E F$ responses are gradually reduced, indicating that it has a tolerance effect. ${ }^{23}$

An increase in the Neutrocytes count by extract in this study might be because of its inflammatory, ${ }^{24,25}$ oxidative stress, ${ }^{26,27}$ adrenocortical function, and sleep physiology ${ }^{28}$ effects. $C E F$ increases adrenocortical function and cortisol secretion. ${ }^{6,29}$ In turn, cortisol increased neutrophil count. ${ }^{30}$ On the other hand, stress increases neutrophil count ${ }^{31}$ and cathinone in $C E F$ causes oxidative stress. ${ }^{26,32} C E F$ induced sleep restriction increases neutrophil count. ${ }^{33,34}$ Like the previous study, ${ }^{10}$ the lower dose of $C E F$ extract reduced lymphocyte count in our study. However, another study revealed that lymphocyte count was increased in schizophrenic patients. ${ }^{35}$ CEF increased dopamine levels in healthy and schizophrenic patients. ${ }^{7}$ Bogale et $\mathrm{al}^{36}$ reported that schizophrenic-like symptoms were observed in mice received $C E F$ extract. In this way, $C E F$ should have increased lymphocyte count, but opposite result was obtained in our study that might be because of variation in the duration of administration.

Reduction in lymphocyte count observed in the current study might be through ECF hematopoietic effects. A previous study indicated that the destruction of dopaminergic cells affected blood cell synthesis. ${ }^{37,38}$ On the other hand, this stimulant affects bioavailability of dopamine in body fluid. ${ }^{7}$ Adrenalin level that affects hematopoiesis could be affected by khat. Another study indicated that sympathetic fibers innervating bone marrow released adrenalin and dopamine affect stem cell activities. ${ }^{28}$ This indicates that dysregulation of adrenergic and dopaminergic fibers might be associated with hematopoietic disturbances.
The higher neutrophil-to-lymphocytes ratio observed in this study could be associated with depression effects of the $C E F^{2,26}$ This ratio is high in patients with severe depression disorder. ${ }^{3}$ Psychiatric disorders associated with subchronic inflammation increased NLR and $C E F$ showed inflammatory responses. ${ }^{3,24,25} C E F$ extract and juice did not affect red blood cell count, hemoglobin concentration, size of red blood cells (sRBCs), and Hematocrit (HCT) in this study (Table 1). However, when the comparison was made between rats received $C E F$ and $\mathrm{AA}$, sRBCs were less in rats at all doses of the extract (Table 1). Nevertheless, Owu et $\mathrm{al}^{39}$ showed that AA (vitamin C, 200 milligrams/kilogram) administered in rats for 28 days reduced sRBCs indicating that the duration of vitamin $\mathrm{C}$ administration could contribute to the differences.

Rats received higher dose of the extract and AA had greater RsV compared with rats received vehicle. Catha edulis Forsk juice also reduced MCHC when compared with vehicle (Table 1). However, in the study conducted before, the PCV and hemoglobin concentration were significantly reduced, while RBCS was increased. ${ }^{10}$ The discrepancy could be attributed to the dose of the extract, duration of administration, and solvent used to extract the plant material. The dose of the Catha edulis Forsk extract used by BinJaliah et $\mathrm{al}^{10}$ was 500 milligram/kilogram and administered for only one week, while the higher dose in our study was 300 milligrams/kilogram administered for twelve weeks. The solvent used in this previous study was hydro-ethanol while diethyl/chloroform ( $\mathrm{v} / \mathrm{v} ; 3: 1)$ was used in our study. Like in our study, Bin-Jaliah et $\mathrm{al}^{10}$ also revealed that $\mathrm{RsV}$ was increased by the crude extract of $C E F$.

In this study, the increase in $\mathrm{RsV}$ in rats received $C E F$ might be the result of the adverse effects of Catha edulis Forsk on the liver. Previous studies indicated that RsV significantly increased in patients with progressive liver fibrosis and inflammation. ${ }^{40,41}$ On the other hand, $C E F$ chewing was associated with acute liver injury, subchronic inflammation and cirrhosis. ${ }^{24,42}$

In this study, $C E F$ juice reduced HgpvRBC (Table 1). Another study also showed $C E F$ reduced HgpvRBCs. ${ }^{24}$ However, Ketema et $\mathrm{al}^{20}$ showed that statistical difference in HgpvRBCs was not observed between mice received the extract and vehicle.

The solvent, animal model and duration of administration difference used by the previous and current study might be the reason for variation in the results. Ketema et $\mathrm{al}^{20}$ used methanol to extract $C E F$ and was administered for four weeks in mice while we used diethyl ether and 
chloroform to extract the leaves and administered for twelve weeks in rats.

Hemoglobin reduction in each RBC observed in this study might be resulted from its effect on iron absorption problems across the gastrointestinal tract. Previous studies indicated that tannins reduced absorption of iron and vitamins; involved in the synthesis of red blood cells. ${ }^{43,44}$ One of the components found in the leaves of $C E F$ is tannin, ${ }^{8,9}$ suggesting that $C E F$ affects iron and vitamin absorption. Another study also showed that $C E F$ reduced level of iron and vitamin B12 in the serum. ${ }^{45}$ Gastrointestinal problems such as esophagitis, gastritis, delaying gastric empty and impaired intestinal absorption, some of the effects of the leaves. ${ }^{2}$ Liver problems induced by $C E F^{24}$ could also be attributed to bleeding problems and iron deficiency among people who are chewing the leaves of $C E F^{46}$

The average HgpRBC reduction in rats received CEF (Figure 1) in our study might be because of its effect on the renal system. Erythropoietin is one of the proteins involved in the synthesis of RBCs and this could be affected by CEF extract. However, Ketema et $\mathrm{al}^{20}$ and BinJaliah et al $^{10}$ also could not see any significant differences in HgpRBC in mice and rats, respectively.

Statistical difference in the total number of platelet has not been seen in our study (Table 1). Alsalahi et $\mathrm{al}^{24}$ and Alele et $\mathrm{al}^{21}$ also found analogous outcomes. But Ketema et $\mathrm{al}^{20}$ reported that its methanolic extract (100 and 200 milligrams/kilogram) administered for four weeks reduced platelet number in mice. Contrarily, a study conducted by Bin-Jaliah et al $^{10}$ revealed that its hydro-ethanolic extract (500 milligrams/kilogram) administered for one week increased platelet count in the rat model. The dissimilarity of these findings might be because of administration duration and extraction solvent variation.

In this study, lower and higher doses of $C E F$ extract increased PCT, while the higher dose increased PsV and aPs. Its juice significantly increased the P-LCR. These findings indicated that $C E F$ increases platelet activities. Strong platelet activity is represented by higher PCT, PsV, and P-LCR. ${ }^{47}$ platelet activities are increased when there is organ inflammation, ${ }^{48}$ anxiety and depression disorders. $^{49}$ On the other hand, an increase in platelet activities and oxidative stress are among the risk factors for thrombosis. ${ }^{50,51}$ This, in turn, indicated that $C E F$ might aggravate organ inflammation, anxiety disorders, and thrombosis. Previous studies indicated that organ inflammation is more prevalent among people who are using $C E F^{25,52}$
AA also increased P-LCR and PsV. Studies indicated that a higher dose of ascorbic acid contributed to oxidative stress, ${ }^{53}$ the release of thromboxane $\mathrm{A}_{2}$ and prostaglandin $\mathrm{E}_{2}$ in subjects with depression and thrombosis. ${ }^{54}$ Platelet activities were higher in patients with depression, schizophrenia and other psychiatric problems and contributed to the secretion of serotonin. ${ }^{55}$

In conclusion, $C E F$ extract, $C E F$ juice, and AA altered some of the hematological indices. AA and $C E F$ increased platelet activities and size variability of red blood cells. The mechanisms of action for these changes need to be studied.

\section{Acknowledgment}

Department of Medical Physiology supported this study. The authors are thankful to Tesfaye Getachew, who supported us during sample collection, and the Ethiopian Public Health Institute for assisting with hematological analysis. Daniel Seyifu Melka is now affiliated with Department of Biochemistry, Division of Basic Sciences, University of Global health Equity, Kigali, Rwanda.

\section{Author Contributions}

All authors made a significant contribution to the work reported, whether that is in the conception, study design, execution, acquisition of data, analysis and interpretation and preparing the manuscript. They have involved in drafting, revising, or critically reviewing the article; gave final approval of the version to be published; have agreed on the journal to which the article has been submitted; and agree to be accountable for all aspects of the work.

\section{Disclosure}

The authors report no conflicts of interest in this work.

\section{References}

1. Tesfaye G, Derese A, Hambsa MT. Substance use and associated factors among university students in Ethiopia: a cross-sectional study. J Addict. 2014;2014:1-8. doi:10.1155/2014/969837

2. Al-Habori M. The potential adverse effects of habitual use of Catha edulis (khat). Expert Opin Drug Saf. 2005;4(6):1145-1154. doi:10. 1517/14740338.4.6.1145

3. Sunbul EA, Sunbul M, Yanartas O, et al. Increased neutrophil/lymphocyte ratio in patients with depression is correlated with the severity of depression and cardiovascular risk factors. Psychiatry Investig. 2016;13(1):121-126. doi:10.4306/pi.2016.13.1.121

4. Odenwald M, Neuner F, Schauer M, et al. Catha edulis forskuse as risk factor for psychotic disorders: a cross-sectional and case-control study in Somalia. BMC Med. 2005;3(5):1-10. doi:10.1186/1741-7015-3-5.2

5. Issa FH, Al-Habori M, Chance ML. Effect of Catha edulis forsk (Catha edulis) use on the bioavailability, plasma levels and antimalarial activity of chloroquine. Med J. 2016;16(2):182-188. 
6. El-Sayed MK, Amin HK. Effect of Catha edulis on insulin, resistin and cortisol levels in type-2 diabetics and nondiabetics. $\mathrm{Am}$ J Biochem Biotech. 2012;8(3):157-163. doi:10.3844/ajbbsp.2012. 157.163

7. El-Sayed MK, Amin HK. Catha edulis chewing effects on the treatment of paranoid schizophrenic patients. Neuropsychiatr Dis Treat. 2015;11:1067-1076. doi:10.2147/NDT.S81011

8. Algabr M, Dunia AM, Aissaoui H, et al. Flavonoids glycosides from leaves of Catha edulis (Celastraceae). Der Pharma Chem. 2015;7 (11):193-196.

9. Al-Alimi KR, Razak A, Saub R, Alabsi AM. Tannins acid, ascorbic acid and fluoride from Catha edulis forskChewing plant. Int $J$ Dent Oral Health. 2017;3(4):1-4. doi:10.16966/2378-7090.240

10. Bin-Jaliah I, Dallak MA, Al-Hashem FH, et al. Derangement of hemopoiesis and hematological indices in Catha edulis forsk(Catha edulis) - treated rats. Afr J Biotech. 2014;13(2):349-355. doi:10.58 97/AJB2013.13373

11. Oliveira CP, Kassab P, Lopasso FP, et al. Protective effect of ascorbic acid in experimental gastric cancer: reduction of oxidative stress. World J Gastroenterol. 2003;9(3):446-448. doi:10.3748/wjg.v9. i3.446

12. Padayatty SJ, Riordan HD, Hewitt SM, Arie Katz L, Hoffer J, Mark L. Intravenously administered vitamin $\mathrm{C}$ as cancer therapy: three cases. CMA. 2006;174(7):937-942. doi:10.1503/cmaj.050346

13. Klimant E, Wright H, Rubin D, Seely D, Markman M. Intravenous vitamin $\mathrm{C}$ in the supportive care of cancer patients: a review and rational approach. Curr Oncol. 2018;25(2):139-148. doi:10.3747/ co.25.3790

14. Aburawi SM, Fathia A, Ghambirlou F, Attumi AA, Altubuly RA, Kara AA. Effect of ascorbic acid on mental depression drug therapy: clinical study. Clin Study J. 2014;4(1):1-8. doi:10.4172/21610487.1000131

15. Moretti M, Budni J, Santos D, et al. Protective effects of ascorbic acid on behavior and oxidative status of restraint-stressed mice. $J \mathrm{Mol}$ Neurosci. 2013;49(1):68-79. doi:10.1007/s12031-012-9892-4

16. Alfaifi H, Abdelwahab SI, Mohan S, et al. Catha edulis forsk (Khat): evaluation of its antidepressant-like activity. Pharmacogn Mag. 2017;13(50):354-358. doi:10.4103/pm.pm_442_16

17. National Institution of Health. Guide for the Care and Use of Laboratory Animals. 8th ed. National Academic Press (US); 2011.

18. Mohammed F, Engidawork E, Nedi T. The effect of acute and subchronic administration of Crude Catha edulis forskExtract (Catha Edulis F.) on weight in mice. ASRJETS. 2015;14(1):132-141.

19. Foster MN, Carr AC, Alina Antony A, Selene PS, Fitzpatric MG. Intravenous vitamin $\mathrm{C}$ administration improved blood cell counts and health-related quality of life of patient with history of relapsed acute myeloid leukaemia. Antioxidants. 2018;7(7):92. doi:10.3390/antiox70 70092

20. Ketema T, Yohannes M, Alemayehu E, Ambelu A. Effect of chronic Catha edulis forsk(Catha edulis, Forsk) use on outcome of Plasmodium berghei ANKA infection in Swiss albino mice. BMC Infect Dis. 2015;15(1):170. doi:10.1186/s12879-015-0911-2

21. Alele PE, Abayomi M, Ajayi AM, Imaniramp L. Chronic Catha edulis forsk(Catha edulis) and alcohol marginally alter complete blood counts, clinical chemistry, and testosterone in male rats. $J$ Exp Pharmacol. 2013;5:33-44. doi:10.2147/JEP.S46635

22. Sharaf A, Farrag AR, Fahmy H. Protective effects of vitamin C on hematological and biochemical parameters of intoxicated male albino rats with lead and cadmium. MEJAST. 2017;7(1):57-67.

23. Nencini P, Ahmed AM, Amiconi G, Elmi AS. Tolerance develops to sympathetic effects of Catha edulis forskin humans. Pharmacology. 1984;28(3):150-154. doi:10.1159/000137956

24. Alsalahi A, Abdulla MA, Al-Mamary M, et al. Toxicological features of Catha edulis (Khat) on livers and kidneys of male and female Sprague-Dawley rats: a subchronic study. Evid Based Complement Alternat Med. 2012;2012:1-11. doi:10.1155/2012/829401
25. Al-Mamary H, El-Shaibany A, Al-Habori M, Al-Meeri A, AlZubairi AS, Al-Mamary M. Effect of Catha edulis on the activities of enzyme markers of carcinogenicity in chemically-induced hepatocellular carcinoma in rabbits. Int $J$ Cancer Res. 2014;10(1):1-13. doi:10.3923/ijcr.2014.1.13

26. Safhi MM, Alam MF, Hussain S, et al. Cathinone, an active principle of Catha edulis, accelerates oxidative stress in the limbic area of Swiss albino mice. $J$ Ethnopharmacol. 2014;156:102-106. doi:10.1016/j.jep.2014.08.004

27. Abdelwahab SI, Alsanosy R, Taha E, Syam MS. Catha edulis forskInduced toxicity: role on its modulating effects on inflammation and oxidative stability. Biomed Res Int. 2018;2018:1-8. doi:10.1155/ 2018/5896041

28. Manzar MD, Salahuddin M, Sony P, et al. Sleep disturbances and memory impairment among pregnant women consuming khat: an under-recognized problem. Ann Thorac Med. 2018;12:247-251.

29. Ahmed MB, El-Qirbi AB. Biochemical effects of Catha edulis, cathine and cathinone on adrenocortical functions. J Ethnopharmacol. 1993;39 (30):213-216. doi:10.1016/0378-8741(93)90039-8

30. Deutsch V, Lerner-Geva L, Reches A, Boyko V, Limor R, Grisaru D. Sustained leukocyte count during rising cortisol level. Acta Haematol. 2007;118(2):73-76. doi:10.1159/000103216

31. Nishitani N, Hisataka Sakakibara H. Association of psychological stress response of fatigue with white blood cell count in male daytime workers. Ind Health. 2014;52(6):531-534. doi:10.2486/indhealth. 2013-0045

32. Al-Zubairi A, Al-Habori M, Al-Geiry A. Effect of Catha edulis (khat) chewing on plasma lipid peroxidation. J Ethnopharmacol. 2003;87 (1):3-9. doi:10.1016/S0378-8741(03)00101-6

33. Boudjeltia KZ, Faraut B, Stenuit P, et al. Sleep restriction increases white blood cells, mainly neutrophil count, in young healthy men: a pilot study. Vasc Health Risk Manag. 2008;4(6):1467-1470. doi:10.2147/VHRM.S3934

34. Rosales C. Neutrophil: a cell with many roles in inflammation or several cell types. Front Physiol. 2018;9(113):1-17. doi:10.3389/ fphys.2018.00113

35. Boneberg EM, Seydlitz EV, Propster K, Watzl H, Rock-stroh B, Illges H. D3 dopamine receptor mRNA is elevated in T cells of schizophrenic patients whereas D4 dopamine receptor mRNA is reduced in CD4+ -T cells. J Neuroimmunol. 2006;173(2):180-187. doi:10.1016/j.jneuroim.2005.11.018

36. Bogale T, Engidawork E, Yisma E. Subchronic oral administration of crude Catha edulis forskextract (Catha edulis forsk) induces schizophernic-like symptoms in mice. BMC Complement Altern Med. 2016;16(153):1-12. doi:10.1186/s12906-016-1145-6

37. Hritcu L. Hematological disorders in 6-hydroxydopamine induced rat model of Parkinson's disease. Turk J Hematol. 2008;25:140-144.

38. Cosentino M, Marino F, Maestroni GJ. Sympathoadrenergic modulation of hematopoiesis: a review of available evidence and of therapeutic perspectives. Front Cell Neurosci. 2015;9(302):1-12. doi:10.3389/fncel.2015.00302

39. Owu DU, Nwokocha CR, Ikpi DE, Ogar EI. Effect of vitamin $\mathrm{C}$ supplementation on platelet aggregation and serum electrolytes levels in streptozotocin-induced diabetes mellitus in rats. Niger J Physiol Sci. 2016;31(1):55-61. Available from: www.njps.com.ng.

40. Cengiz M, Candır BA, Yılmaz G, Akyol G, Ozenirler S. Is increased red cell distribution width an indicating marker of nonalcoholic steatohepatitis and fibrotic stage? World J Gastroenterol. 2013;19 (42):7412-7418. doi:10.3748/wjg.v19.i42.7412

41. Xu WS, Qiu XM, Ou QS, et al. Red blood cell distribution width levels correlate with liver fibrosis and inflammation A noninvasive serum marker panel to predict the severity of fibrosis and inflammation in patients with hepatitis B. Medicine. 2015;94(10):1-7.

42. Alhaddad OM, Elsabaawy MM, Waked IA. Catha edulis forskIntertwined liver damage. J Infect Dis Ther. 2017;5(5):1-3. doi:10.4172/2332-0877.1000337 
43. Carrera G, Mitjavila S, Derache R. Effect of tannic acid on vitamin B 12 absorption in rats. Sci Hebd Seances. 1973;276(2):239-242.

44. Afsana K, Shiga K, Ishizuka S, Hara H. Reducing effects of ingesting tannic acid on the absorption of iron but not zinc, copper and magnesium by rats. Biosci Biotec Biochem. 2004;68(3):584-592. doi: $10.1271 / \mathrm{bbb} .68 .584$

45. Al-Dubai W, Al-Ghazaly J, Al-Habori M, Saif-Ali R, Mohammed A. Catha Edulis (Khat) chewing decreases serum levels of iron, ferritin and vitamin B12 and increases folic acid. Int J Vit Nutr Res. 2014;84 (5-6):223-228. doi:10.1024/0300-9831/a000208

46. Gkamprela E, Deutsch M, Pectasides D. Iron deficiency anemia in chronic liver disease: etiopathogenesis, diagnosis and treatment. Ann Gastroenterol. 2017;30(4):405-413.

47. Swaminathan A, Amitkumar K, Ganapathy S, Ayyavoo S. Evaluation of the impact of cigarette smoking on platelet parameters. Natl J Physiol Pharm Pharmacol. 2015;5(5):426-430. doi:10.5455/njppp. 2015.5.1009201570

48. Budak YU, Polat M, Huysal K. The use of platelet indices, plateletcrit, average size of platelets and Platelet size variability in emergency non-traumatic abdominal surgery: a systematic review. Biochem Med. 2016;26(2):178-193. doi:10.11613/BM.2016.020
49. Almis BH, Aksoy I. Average size of platelets level in patients with generalized anxiety disorder. Psychiatry Clin Psychol. 2018;28 (1):43-47. doi:10.1080/24750573.2017.1385210

50. Zhang X, Cui -M-M, Fu S, et al. Platelet size variability correlates with the prognosis of gastric cancer. Oncotarget. 2017;8(12):20 13-20219.

51. Gawlita M, Wasilewski J, Osadnik T, Reguła R, Bujak K, Gonera M. Average size of platelets and platelet-large cell ratio as prognostic factors for coronary artery disease and myocardial infarction. Folia Cardiol. 2016;10(6):418-422. doi:10.5603/FC. 2015.0079

52. Nigussie T, Gobena T, Mossie A. Association between Catha edulis forskchewing and gastrointestinal disorders: a cross-sectional study. Ethiop J Health Sci. 2013;23(2):123-130.

53. Sadighara P, Salar-Amoli J. High concentrations of vitamin C induce oxidative stress in blood. Biharean Biol. 2009;3(1):33-35.

54. Mohammed BM, Sanford KW, Fisher BJ, et al. Impact of high dose vitamin C on platelet function. World J Crit Care Med. 2017;6 (1):37-47. doi:10.5492/wjccm.v6.i1.37

55. Ehrlich D, Humpe C, Platelets in psychiatric disorders. World J Psychiatr. 2012;2(6):91-94. doi:10.5498/wjp.v2.i6.91
Journal of Blood Medicine

\section{Publish your work in this journal}

The Journal of Blood Medicine is an international, peer-reviewed, open access, online journal publishing laboratory, experimental and clinical aspects of all aspect pertaining to blood based medicine including but not limited to: Transfusion Medicine; Blood collection, Donor issues, Transmittable diseases, and Blood banking logistics; Immunohematology; Artificial and alternative blood based
Dovepress

therapeutics; Hematology; Biotechnology/nanotechnology of blood related medicine; Legal aspects of blood medicine; Historical perspectives. The manuscript management system is completely online and includes a very quick and fair peer-review system. Visit http://www.dovepress.com/testimonials.php to read real quotes from published authors. 